\title{
Young Children Use Discovery and Creation Significantly More Than Adults for Deciding Ownership
}

\author{
Gustavo Faigenbaum ${ }^{D},{ }^{1}$ Mariano Sigman, ${ }^{2,3,4}$ and Leandro Pablo Casiraghi ${ }^{2,3}$ \\ ${ }^{1}$ Universidad Autónoma de Entre Ríos, Gualeguaychú, Entre Ríos, Argentina \\ ${ }^{2}$ Universidad Torcuato Di Tella, Buenos Aires, Argentina \\ ${ }^{3}$ Consejo Nacional de Investigaciones Científicas y Tecnológicas (CONICET), Argentina \\ ${ }^{4}$ Facultad de Lenguas, Educación, Universidad Nabrija, Madrid, Spain \\ Correspondence should be addressed to Gustavo Faigenbaum; gusfai@gmail.com
}

Received 13 August 2018; Revised 2 November 2018; Accepted 6 December 2018; Published 19 December 2018

Academic Editor: Andrew N. Meltzoff

Copyright ( 2018 Gustavo Faigenbaum et al. This is an open access article distributed under the Creative Commons Attribution License, which permits unrestricted use, distribution, and reproduction in any medium, provided the original work is properly cited.

\begin{abstract}
The present study attempted to determine differences between children and adults in the resolution of third-party property disputes involving different claims for ownership. Children $(\mathrm{n}=110$; mean age $\pm \mathrm{SD}=6.3 \pm 1.2)$ and adults $(\mathrm{n}=74 ; 37.5 \pm 12.6)$ watched videos depicting ownership conflicts between two characters who held opposing claims over an object and were asked to decide who should own it. In the stories, each character based her claim on one of four distinct arguments: Discovery, Creation, Occupation, and Transaction. A key difference between these claims lies in the presence or absence of a "first possession" element: Discovery and Creation imply prior possession of the discovered or created object, whereas Occupation and Transaction necessarily involve a preexisting owner. We found that children assigned ownership to prior possessors in the stories twice as much as adults (Medians $=4$ and 2 , out of four cases, respectively; $\mathrm{p}<0.001$ ) and favored discoverers and creators substantially more than adults. Previous studies have demonstrated the importance of first possession in the adjudication of ownership for both children and adults. The present study deals with first possession as instantiated in Discovery and Creation episodes and provides novel quantitative evidence that children value first possession significantly more than adults. In contrast with previous studies, we found that discovery trumps creation in certain contexts, suggesting that narrative and contextual details influence children's reasoning.
\end{abstract}

\section{Introduction}

1.1. Ownership Claims. In order to navigate the social world, children need to master ownership rules [1]. A subset of those rules is concerned with determining who owns what $[2,3]$. For example, if one buys, discovers, builds, or makes use of an object for an extended period of time, one usually comes to be recognized by other people as the object's owner. Yet, there are qualifications and exceptions to these rules. Societies enforce complex systems of laws and procedures to determine who owns what, as well as the specific rights ownership bestows. Additionally, rules are needed to solve inevitable conflicts between multiple claimants to the same object.

How does an individual become the legitimate owner of an object? Merrill and Smith [4] enumerate several methods to acquire property (the examples are ours):
(1) First possession: someone spots and plucks an apple from a tree.

(2) Discovery: a miner finds gold; a scientist discovers a cure for cancer.

(3) Creation: a carpenter builds a chair; an artist paints on a canvas.

(4) Capture: a fisherman catches some fish.

(5) Accession: oil starts flowing from under the ground at someone's property.

(6) Find: a walker comes across a cell phone in the street and it is impossible to identify a previous owner.

(7) Adverse possession: a farmer occupies a tract of land for 20 years without knowing that the land belongs 
to someone else, all the while behaving as an owner would (paying taxes, taking care of the property, etc.)

(8) Transfer from a previous owner: a woman receives golf clubs for her birthday; a man buys shoes at a store; a man dies, and his daughter inherits his car.

This catalog is not comprehensive, and it is easy to imagine episodes that do not fit nicely in any of the above categories or that fit in more than one. Yet, the list does help us to classify some of the ownership arguments used spontaneously by children and adults in everyday settings. A contrast can be drawn between principles that explain how property comes into existence (1 through 5$)$ and principles that explain how an object changes owner (6 through 8). In addition, principles that rely on first possession can be distinguished from principles that do not. Thus, in discovery and capture the agent is necessarily a first possessor, whereas in find, adverse possession, and transfer she is not (since property changes hands from a previous to a subsequent owner). Creation and accession are intermediate cases, since those principles apply to situations where new goods originate from preexisting goods that already were someone's property (e.g., a carpenter builds a table with wood and nails that were someone else's). Finally, we may differentiate between cases in which property changes hands because a previous owner voluntarily relinquished it (gift, sale) and cases in which the original owner's will is not considered (find, adverse possession).

Because there are different reasons for ownership (creation, discovery, gift, occupation, etc.) and because some situations are ambiguous, it is common for two individuals to claim ownership of the same object. Often the clash is resolved by brute force. At other times, individuals use arguments to justify their property rights; they say things like "I saw it first," "I made it myself," or "dad gave it to me." Is there a method to determine which party has the most decisive argument? Perhaps some types of ownership claims are more relevant than others. There might be a hierarchy of ownership principles according to which, for example, "creation" trumps "discovery" (or the other way around).

1.2. The Present Study. The goal of the present study is to identify the main principles acknowledged by children and adults while reasoning about ownership conflicts. We aim at extending the work of Rochat et al. [5], who already attempted a systematic comparison among different types of ownership claims in children from different cultures. To this end, we use scripts that illustrate the following four ownership principles:

(1) InDiscovery, the person who discovers something is, by definition, the original owner; no ownership transfer is involved.

(2) InCreation, the person who builds something new is the original owner of the thing created. However, the raw materials may have a history of previous ownership. The creator may be the original owner of the materials used or they may have previously belonged to someone else.
(3) InAdverse Possession orOccupation, the object or land is transferred from a previous owner to a new one, without the acquiescence of the previous owner.

(4) InTransactions, such as gifts and sales, a previous owner willfully passes property on to a new owner. Gifts and sales are consensual.

For practical purposes, we limited our testing to these four principles which cover all important conceptual contrasts. Our aim was to examine how these four principles, which are frequently used in legal contexts [6], are applied by children and adults to establish their relative weight in their reasoning about ownership conflicts. In other words, we asked: does discovery trump creation? Does creation trump occupation? And so on for all possible combinations among the four principles.

1.3. First Possession in Legal, Cultural, and Psychological Contexts. The principle of first possession, or "first in time, first in right," grants ownership to the party that gains control of the object before other potential claimants. This method of establishing property is a fundamental component of most legal systems. It applies to varied settings such as abandoned property, fisheries and wildlife, groundwater, land, oil and gas, the radio spectrum, spoils of war (including prisoners), treasure trove, water rights, and intellectual property, among many others [6]. First possession allows agents to create property ex nihilo: what initially belongs to no one becomes the property of the first taker. "The captor of wild animals, or the taker of fish from the ocean, has not merely possession, but a title good against all the world" [7, p. 245].

Famous court cases illustrate the importance given to possession for the establishment of ownership. In the 1805 case Pearson v. Post, the catcher of a fox was granted ownership over a man who had started chasing it earlier. In Popov v. Hayashi, Barry Bond's record-breaking home run baseball was first caught by Alex Popov, who dropped it after being mobbed by a group of individuals, and it was then grabbed by Patrick Hayashi. The court ordered in 2002 that the ball be sold and the profits divided equally between both men since both had been rightful possessors.

First possession is tightly woven into our everyday habits. For example, we ardently demand a restaurant table because we arrived first or even because we saw it first. We also consider ourselves as owners of an idea simply because we "had it" (meaning "it occurred to us") first. First possession is ubiquitous, and it underlies both children's appeals to "finders keepers" and nations' claims of sovereignty on the grounds that their explorers were first to set foot on virgin territories.

Many philosophers share similar intuitions about the relationship between possession and ownership. For example, Hegel [8], in his Philosophy of Right, argues that property is first constituted by a person's taking possession of an object. A person can take possession by simply grabbing an object; she thus exercises a bodily control of the thing and demands that other people refrain from interfering with her exclusive enjoyment of it. It might seem strange to give such a central role to physical grabbing, since in modern society we obtain most of our belongings by means of 
commercial transactions (i.e., we buy them). Yet, even in our hypercommercial societies, where we purchase most of what we need, the principle of first possession plays an important role in ownership reasoning.

A number of studies have shown that the principle of first possession is central to both children's $[5,9,10]$ and adults' [11] reasoning about ownership. Developmental researchers have shown that the notion that possession produces ownership is already present in young children and stays with us throughout our adult life. For example, a study by Bakeman and Brownlee [12] found that the fact that a toddler played with a toy moments ago increases her chances of winning a possession conflict against another child that wants to use the same toy; in other words, previous possession appears to create an entitlement (see also $[13,14])$.

Whereas Bakeman and Brownlee [12] focused on children's possession conflicts in the context of peer interaction, other researchers, working with a sociocognitive approach, studied how children judge who owns what in a given context. Friedman and Neary [2] studied children's abilities to infer who owns what from contextual cues and found that children ( 3 and 4 years old) assume that the first person they see possessing an object is its owner, even when ignoring the object's previous history of possession, an assumption shared by adults [11]. Kim and Kalish [15] pitted prior possession against transfers (sales and gifts) and found that although preschool children correctly identify the new owner, they still grant the original owner some control over the object. Verkuyten, Sierksma, and Thijs [16] studied the use of the "first arrival" principle in disputes about land ownership in children between 9 and 12 years of age. First arrival to a land is analogous to first possession of objects. Their study concluded that "children believe that a person owns a particular land relatively more when that person arrived first." Furthermore, the first arriver is considered to own the land relatively more even when she did not work the land, compared to the later arriver who did work it; first arrival outweighs the laboring of the land of the later arriver.

\subsection{First Possession Is Always Mixed with Other Principles.} There is no doubt that first possession is a very important factor in everyday ownership reasoning. However, we decided not to include first possession as such among the four ownership principles tested in the experimental situations.

In real life, first possession does not occur in a pure form but is always part of a broader situation. If one discovers a hidden treasure, a cave in a mountain or a new treatment against cancer, one is a first possessor, but also a discoverer. If one builds a house or paints on a canvas, one is a first possessor, but also a creator. Thus, it is difficult to disentangle reasons such as "I had it first" from other reasons such as "I built this" or "I discovered this"; they all appear connected in the discourse of first possessors defending their property.

John Locke's (1690) famous labor theory of property illustrates how porous the limits between first possession and other ownership principles are. According to Locke, each man has a natural right to himself and his own body and can gain ownership of natural resources such as land or game by mixing his labor with the resource. For example, a man can acquire ownership of a plot of virgin land by cultivating it. At first glance, Locke seems to be arguing that ownership is a consequence of having invested a certain amount of effort; possession without labor (e.g., without cultivating the land) is not sufficient to support ownership claims. Yet, he also makes it clear that it is the first agent who takes control of a natural resource that gains ownership over it. It is true that the apple becomes mine only when I use my own body to pluck it from the tree. But, in this and some other examples, the labor invested is minimal, and the crucial factor is that I picked the apple before anybody else. Thus, several commentators argue that Locke's labor theory is akin to a theory of first possession (see, for example, [17]).

Is it possible to design an experiment to disentangle first possession from related principles, such as creation and discovery? Levene, Starmans, and Friedman [18] tried to do exactly this. They tested adults by using ingenious situations that aim at illustrating an act of creation without possession. For example, in one of the stories they used, someone creates a work of art by throwing a bucket of paint against a board without touching it; next, a second person passes by and grabs the painting. Who is the owner, then, the person who created the artwork (by throwing paint) or the person who grabbed it first? The authors conclude that creation plays a greater role in adults' judgments of ownership than other competing principles such as first possession, invested labor, or increases in the object's value: "Creation trumps first possession as a means of acquiring ownership at least when creation precedes first possession."

Legal theorists, however, do not define possession as the physical act of touching or grabbing an object, but as the act of controlling something, along with an intention to do it. "Valuable resources are regarded as originally existing in (...) the public domain- a state of affairs in which valuable resources exist but no one has ownership over them. Ownership is awarded to the first person who demonstrates a sufficient degree of control over some portion of these resources to be deemed to be in 'possession' of them" [19]. Similarly, the Encyclopedia Britannica defines possession as "the acquisition of either a considerable degree of physical control over a physical thing (...) with the definite intention of ownership," and the first definition of possession according to the Merriam-Webster dictionary is "the act of having or taking into control." If I set up a water tank to collect rainwater, the water is mine even though I have never touched it, because I have a "sufficient degree of control" over the tanks, and therefore over the water. In that sense, I "have" the water. If I set a trap in a wild woodland, any animal caught in it would be considered mine even before I get it out of the trap and take it with me. In contrast, in Pearson v. Post the chaser had no control over his desired game.

The case of someone splattering paint on a board is analogous to the aforementioned cases in that they illustrate possession without physical contact; in both cases, the agent is controlling the object without touching it. In the vignettes in Levene et al.s [18] paper, even if creation is done at a physical distance, it involves object control. The agent who tosses paint against a canvas is controlling the paint, the canvas, and the resulting product with a certain intention 
and can be deemed as a possessor in that sense. If the creator is a possessor, then Levene et al.s [18] script fails to test for creation without possession, and hence the conclusion that "pure" creation trumps "pure" first possession is unwarranted. In the real world, these principles are never unmixed. Creation always implies object control to a certain degree.

In everyday life, determining the possessor of a thing is often an intuitive and straightforward matter. Despite this apparent simplicity, possession cannot be reduced to a brute, physical fact: identifying a possessor requires considering the agents' actions and intentions within a normative cultural context. This is exemplified by an anthropological study by Marshall [20]. While researching the !Kung Bushmen of South Africa she found that when they hunt, "the owner of the animal is the owner of the first arrow to be effectively shot into the animal so that it penetrates enough for its poison to work." The owner is not the head of the band, the person who organized the hunt, or the person who shot the arrow, but the owner of the arrow. Ownership of the tool becomes, by extension, ownership of the hunted animal. First possession comes in many flavors.

1.5. Possession as a Cultural Phenomenon. Psychological research supports an account of possession that includes social norms and intentions. Friedman [21] has shown that adults value intentions and actions necessary for possession over physical contact when deciding ownership. Kanngiesser, Gjersoe, and Hood [22] made two individuals borrow clay objects from each other in order to mold them into new objects. Participants were more likely to transfer ownership to the second individual after she invested creative labor in the object than after other manipulations (holding the object, making small changes to it). This effect was significantly stronger in preschool children than in adults. "We found that for children, the main component of creative labor was the invested effort, and the secondary component of creative labor was changing an object's identity." The study thus suggests that children are tuned to relevant social actions such as significant transformations of the object, and not to mechanistic factors such as "duration of possession," "physical proximity," or "contact with the object," when deciding ownership.

Rochat et al. [5] compared different types of ownership claims in children from different cultures. In their pioneering study, each child was presented with a series of scripts involving two identical dolls fighting over an object. The child had to decide which of the two dolls should own the object. Each script enacted a potential reason for attributing ownership: creation, familiarity, first contact, or equity. For example, in one of the scripts, a doll claims to have created the object, while the other only asserts that the object is hers without providing a competing reason. Results show that across cultures children are significantly more consistent in attributing ownership when one of the protagonists created the object, as compared with other kinds of reasons such as first contact, familiarity with the object, or equity considerations. "Creation" appears to be more stable across cultures than the other criteria.
How did Rochat et al. [5] select those specific four types of ownership claim? "Creation" is uncontroversial: it is ubiquitous both in legal literature and in psychological research. "Familiarity" and "first contact" seem to map aspects of first possession. "Equity" is not a customary, well-established reason for acquiring ownership in modern, Western societies. Still, "equity" might be a good reason for requesting resources in the context of a distribution [23]: for example, one might give financial aid or charge lower taxes to the needy. Thus, cross-cultural research suggests that some traditional societies with low market integration favor equitable methods for the distribution of food and other resources [24].

Our own selection of four types of ownership claims is based on legal doctrine. Our goal was to produce stories reflecting the main conceptual tensions at play in typical ownership conflicts. The present study focuses on four ownership claims: discovery, creation, transaction, and occupation. While we are interested in the role of first possession in ownership reasoning, we do not ask participants about first possession directly. Rather, we construe first possession as a principle that is inherent to discovery and creation claims. Another distinctive feature of our study is that we try to determine how much children rely on each type of ownership claim in comparison with adults.

Developmental psychology, legal theory, anthropology, and philosophy all agree on the relevance of first possession. However, we decided to assess the weight of first possession in children's and adults' ownership reasoning by using scripts that illustrated other principles which incorporate first possession to different degrees. Discovery involves first possession. Creation implies first possession of the item created but is compatible with a previous possession of raw materials. Occupation and Transaction necessarily entail that the current possessor is not the original one. In this way, we were able to limit the number of principles being tested to four, while covering all main conceptual aspects of ownership.

\section{Material and Methods}

2.1. Ethics. All the procedures in this study were approved by the Ethical Committee for Research from the Center of Medical Education and Clinical Research (CEMIC) "Norberto Quirno" (Buenos Aires, Argentina).

2.2. Materials. Each story presented two children who held opposing ownership claims about an object. The stories portrayed the four different types of ownership claim previously described in the Introduction: Discovery (D), Creation (C), Transaction $(\mathrm{T})$, and Occupation $(\mathrm{O})$.

Since there were four types of claims, and each story contrasted two of them, we wrote six stories in order to contrast each claim with the other. Each conflict is referred to by naming the characters in the story in chronological order; for example, in Discovery vs. Occupation, the first character is the person who makes the discovery and the second the one that later occupies the object under dispute: 

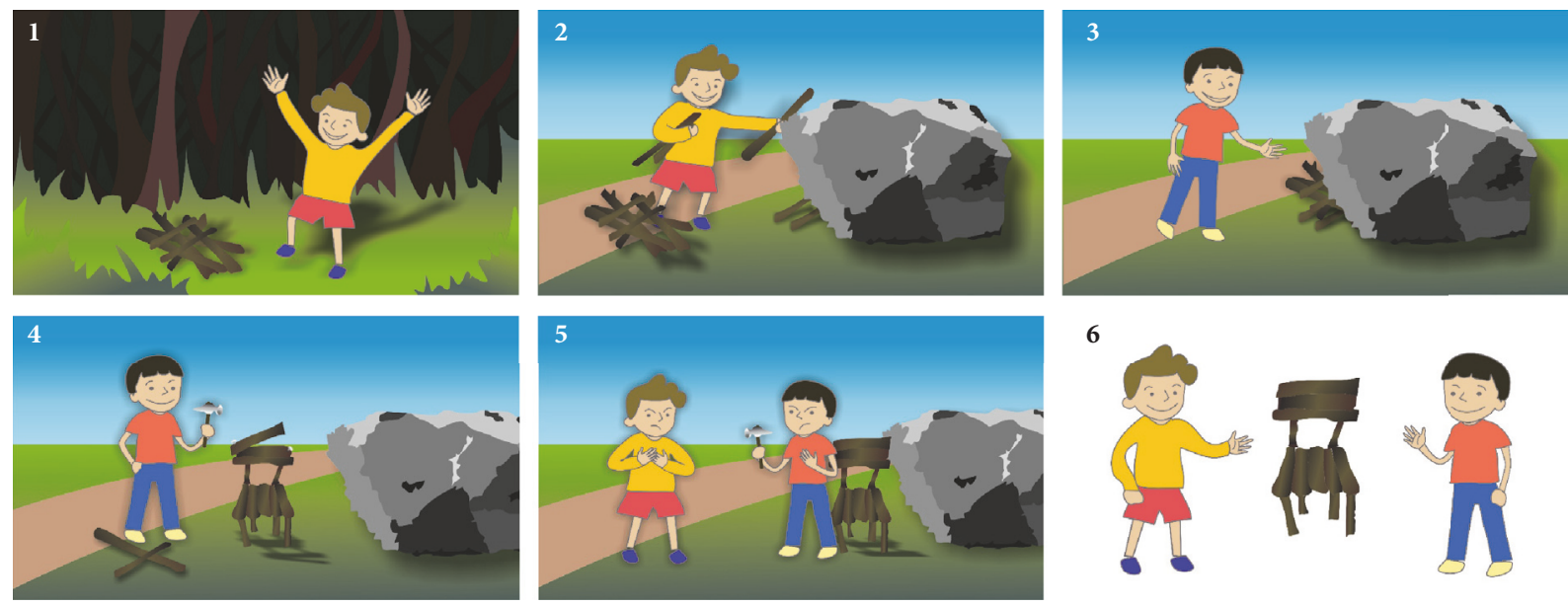

Figure 1: Vignettes and script for the Discovery vs. Creation story. The numbers between brackets indicate the vignette that accompanied the narration: (1) "One day, Luis was walking by the forest. It was a dark place, full of trees and plants. Nobody had ever reached that sector of the forest. While walking, Luis found a bunch of wood pieces: 'This is great! This wood is nobody's, so I'll take it. Now it's mine'. Luis was the first one to find those pieces of wood, pick them up, and say they were his." (2) "Luis took the wood pieces to a nearby path and put them behind a big rock. After that, he continued walking." (3) "Later, Nico walked by that place and saw the wood pieces that Luis had put behind the rock." (4) "Nico said: 'Wow, a bunch of wooden pieces! I am going to build a chair'. Then, Nico built a chair with the pieces of wood. He did it in a short time. It was a weak, uncomfortable, and ugly chair. If a big person would have sit on the chair, it would have broken down." (5) "Sometime later, Luis came back, saw the chair and said: 'My wood pieces!' But Nico answered: 'It's my chair!' Luis said: 'The chair is mine because I found and picked up those wooden pieces. They are mine'. And Nico answered: 'The chair is mine because I made it. It's mine'. And they could not reach an agreement." Afterward, the sixth vignette was shown and children were asked: (6) “Whose chair is this? (Spanish: '¿De quién es la silla?') Is it Juan's, who discovered the wood, or is it Luis', who built the chair?".

(1) Discovery vs. Creation: A boy discovers some pieces of wood and puts them aside; a second boy arrives and manufactures a chair with them.

(2) Discovery vs. Occupation: A girl discovers a cave in a mountain. Later, a second girl finds the cave and starts living there.

(3) Discovery vs. Transaction: A boy discovers a gold coin and gives it to a friend, but later he wants it back.

(4) Creation vs. Occupation: A girl builds a little wood house out of abandoned materials but does not move in. A second girl sees the house and moves in.

(5) Transaction vs. Creation: A girl buys some materials from a friend but leaves them on the street. A second girl uses the materials to build a table.

(6) Transaction vs. Occupation: A boy receives a house from a friend but does not move in. A second boy moves into the house.

In all the stories, both characters claimed ownership of the disputed object and argued about it. Half of the stories involved boys while the other half involved girls, to avoid a potential confound of gender in judgments. The characteristics of each type of claim constrained the scripts to some extent. For example, discovery necessarily means that the person making the claim is the first possessor of the object. Occupation, by way of contrast, always implies a previous possessor. In creation, the person making the object is the first possessor of it, yet this is compatible with a previous owner of the materials used for building the new object. Transaction always assumes a previous owner, the person who gave the object away.

A pilot study on a different adult sample was conducted to determine the most appropriate stories that would be used for the main study ( $\mathrm{n}=105$, age $M=31.76, S D=10.1$, females $=57 \%$ ). The objective of this preliminary study was to tune the details of the set of stories so adult responses would be more or less balanced (i.e., close to a $50 \%$ split of decisions), in order to later allow us to determine children's relative preferences either above or below of those of adults in each conflict. Importantly, the data from this pilot study was only used in the design stage of the present work and was not considered any further. A detailed description of the pilot study is presented in the Supplementary Material.

After the final scripts were defined, a six-vignette storyboard was designed for each story by a graphic artist. The sequence was organized so that the first two vignettes portrayed the participation of the first character, the third and fourth vignettes the actions of the second character (including, for each character, the evaluative comments selected from the pilot study), and the fifth vignette presented the argument between the two children (see an example in Figure 1). A final sixth figure was presented depicting both characters on each side of the claimed object, which was in the middle of the two children (to keep consistency with the story and the presented vignettes, the first character was always to the left of the object while the second one was to the right; see the last vignette from Figure 1). Audio tracks of the scripts narrated by an actress were used to prepare video versions of the stories. Characters were drawn with distinguishable 
TABLE 1: Overview of participants.

\begin{tabular}{lccccc}
\hline Population & & Age $M(S D)$ & Female & Male & Total \\
\hline \multirow{4}{*}{ Children } & K4 & $4.9(0.4)$ & 11 & 17 & 28 \\
& K5 & $5.9(0.4)$ & 16 & 15 & 15 \\
Adults & FG & $6.9(0.4)$ & 10 & 12 & 25 \\
& SG & $7.1(0.4)$ & 14 & 26 \\
\hline
\end{tabular}

looking features so that it would be easy for children to remember and identify each of them. Two versions of each video were prepared in which characters (and their given names) appeared as either the first or the second children in the story to control for effects of characters' names and looks. Videos length ranged from approximately 1:10 to 1:40 and averaged 1:25. The full set of videos files can be found at https:/goo.gl/A7Sudo (in Spanish). Original scripts in their translated versions are included in full in the Supplementary Material.

The definitive script and vignettes for the Discovery vs. Creation conflict are presented in Figure 1 as an example.

\subsection{Participants}

2.3.1. Children. A hundred and fifteen children from a middle-class private school in Gualeguaychú (Entre Ríos, Argentina) were recruited for the study. Children's parents received complete information about the nature of the study and gave written consents to allow for the participation of children. A total of five children did not attend school on the days on which the interviews were held, so they did not participate in the study. Children $(N=110$, age range $=4.4$ to $8.6, M=6.4, S D=1.3$, females $=46 \%$; see Table 1 for details) corresponded to the two upper kindergarten levels (four- and five-year-old kindergarten levels; K4 and K5, respectively) or the two lower primary-school levels, first- and second-grade (FG and SG, respectively; $n$ : $\mathrm{K} 4=28, \mathrm{~K} 5=31, \mathrm{FG}=25$, and $\mathrm{SG}=26)$. This age range was chosen for comparison purposes with previous studies $[2,5,9]$. In addition, we were interested in working with children as young as possible, and in pilot tests we found that 4-year-olds were the youngest children that were able to understand the scripts and answer questions about them.

Children were interviewed individually in a familiar quiet room in their school by trained assistants who were blind to the objectives of the study. All children watched four of the movies on laptop computers; the movies were ordered according to the criteria detailed below. The decision to show only four videos was aimed at reducing the duration of the interviews and hence retaining the children's interest and attention to the activity. While the final figure with the two characters and the object was being presented, the children were asked who should own the object under dispute. For example, for the Discovery vs. Creation story, they were asked: "Whose chair is this? (Spanish: '¿De quién es la silla?') Is it Juan's, who discovered the wood, or is it Luis', who built the chair?" Once children clearly indicated one of the characters (either by naming or by pointing at the corresponding figure in the screen), the interviewer asked: "Why do you think so?" If a child gave no answer to the first question, the interviewer continued to the next video, and a "no answer" response was recorded for the conflict (only one child in the whole sample skipped answers to two of the four stories).

2.3.2. Adults. Adult volunteers recruited through our laboratory social networks site $(N=74$, age $M=37.6, S D=$ 12.7 ; females $=61 \%$; see Table 1 for details) received randomly assigned links to Google Forms and filled them anonymously from their personal computers. After filling an informed consent and entering age and gender data, they were told that they were going to watch movies involving ownership conflicts between two children. As in the interviews with children, adults watched a total of four videos. Stories were again ordered for each volunteer according to the criteria described below. Each story was presented using the exact same videos shown to the children. After each video, the corresponding figure with both characters and the disputed object between them was presented and participants were asked the very same questions presented to children.

\subsubsection{Criteria for the Ordering of Stories and Versions.} Because the experiment involved six different conflicts and two video versions for each of these (in which characters in the story were swapped), the total number of videos was 12 . To control for the effect of the order of presentation in the experiment, twelve four-story sets were prepared in a way that any given version of any of the stories would appear in all of the four possible positions in the order. In addition, the second and fourth stories always involved the two claims absent in the previous ones (e.g., if the first or third story presented one of the versions of Discovery vs. Creation, the second or fourth was one of the versions of Transaction vs. Occupation).

While this strategy did not cover all possible combinations of stories and versions, it prevented potential interference derived from the repetition of claims and situations that may be expected from a truly randomized ordering. These criteria also ensured that all children and adults decided over two and only two stories involving each of the claims.

\section{Results}

After watching the narrated videos depicting the conflict, children and adults were asked to decide which character should be the owner of the disputed object. Children favored the first character in the stories $(M d n=4$, out of four stories) 
TABLE 2: Summarized data and statistical analysis of decisions for all conflicts in children and adults.

\begin{tabular}{|c|c|c|c|c|c|}
\hline \multirow{2}{*}{ Conflict } & \multicolumn{2}{|c|}{ Children } & \multicolumn{2}{|c|}{ Adults } & \multirow{2}{*}{ Children vs. Adults } \\
\hline & $1 s t / T$ & Binomial & 1st/T & Binomial & \\
\hline \multirow[t]{3}{*}{ D vs. C } & $51 / 72$ & $p<.0005$ & $15 / 51$ & $p=.0046$ & $p<.0001$ \\
\hline & & $R R=1.42$ & & $\mathrm{RR}=0.60$ & $\chi^{2}=20.60$ \\
\hline & & & & & $R R=2.408$ \\
\hline \multirow[t]{3}{*}{ D vs. O } & $68 / 73$ & $p<.0001$ & $23 / 55$ & $p=.2806$ & $p<.0001$ \\
\hline & & $R R=1.86$ & & & $\chi^{2}=40.22$ \\
\hline & & & & & $R R=2.228$ \\
\hline \multirow[t]{3}{*}{ D vs. T } & $67 / 74$ & $p<.0001$ & $24 / 42$ & $p=.4408$ & $p<.0001$ \\
\hline & & $R R=1.81$ & & & $\chi^{2}=17.68$ \\
\hline & & & & & $R R=1.584$ \\
\hline \multirow[t]{3}{*}{ C vs. O } & $68 / 74$ & $p<.0001$ & $26 / 42$ & $p=.1641$ & $p<.0001$ \\
\hline & & $R R=1.84$ & & & $\chi^{2}=15.68$ \\
\hline & & & & & $R R=1.484$ \\
\hline \multirow[t]{2}{*}{ T vs. C } & $58 / 73$ & $p<.0001$ & $36 / 54$ & $p=.0300$ & $p=.0759$ \\
\hline & & $R R=1.60$ & & $R R=1.33$ & $\chi^{2}=3.151$ \\
\hline \multirow[t]{2}{*}{ T vs. O } & $55 / 72$ & $p<.0001$ & $38 / 51$ & $p=.0006$ & $p=.8110$ \\
\hline & & $R R=1.53$ & & $R R=1.49$ & $\chi^{2}=0.057$ \\
\hline \multirow[t]{2}{*}{ D vs. all others } & $186 / 219$ & $p<.0001$ & $62 / 148$ & $p=.0583$ & $p<.0001$ \\
\hline & $(M d n=2 / 2)$ & $R R=1.70$ & $(M d n=1 / 2)$ & & $U=1609$ \\
\hline \multirow[t]{2}{*}{ 1st vs. 2nd } & $367 / 438$ & $p<.0001$ & $162 / 296$ & $p=.1164$ & $p<.0001$ \\
\hline & $(M d n=4 / 4)$ & $R R=1.68$ & $(M d n=2 / 4)$ & & $U=1801$ \\
\hline
\end{tabular}

Note. The second and third columns show the split of decisions in each conflict as the number of judgments favoring the first character over the total number of answers $(1 \mathrm{st} / T)$, and the summary of all the stories involving the Discovery claim $(D$ vs. all others $)$ and the summary of total answers for the six conflicts $\left(1^{\text {st }}\right.$ $\left.v s .2^{\text {nd }}\right)$. Within-groups analysis was performed through Binomial tests assuming a random distribution of cases. The fourth column displays the comparisons between decisions of adults and children: differences in individual stories were analyzed through Chi-square tests; differences in the $D$ vs. all others and $1 s t$ vs. 2nd summaries were analyzed through Mann-Whitney U tests.

$R R$ : Relative risk.

in significantly more cases than adults $(M d n=2$; MannWhitney $U=1801, p<.001$; Table 2). Discovery was the claim that presented the greater strength difference between adults and children. When all conflicts involving Discovery are summarized, children decided in favor of discoverers twice as many times as adults $(M d n=2$, out of two stories; and $M d n=1$, respectively; Mann-Whitney $U=1609, p<.001$; Table 2).

For the sake of simplicity, we will refer to each conflict using an " $X v s$. $Y$ " format to refer to each conflict according to the claims involved: Discovery (D), Creation (C), Transaction $(\mathrm{T})$, and Occupation $(\mathrm{O})$.

Children consistently judged first or prior possessors in the stories as the owners significantly above the $50 \%$ chance in all six conflicts, according to two-tailed binomial tests. Adults, on the other hand, showed above significance splits of judgments only in the $D v s$. $C$ (favoring the creator), the $T v s$. $C$, and the $T$ vs. $O$ conflicts (in both favoring the transferee). We then compared the responses of children and adults to each conflict. Children decided in favor of the first characters in the stories significantly more often than adults in the $D v s$. $C, D$ vs. $O, D$ vs. $T$, and $C v s$. $O$ stories (Chi-square tests, $p<$ .0001 for all four). The complete data is presented in Table 2 along with the statistical analysis.

No effects on judgments were found for gender (Supplementary Table 1) or order of presentation (Supplementary
Table 2) in adults or children in any of the conflicts. Age had significant effects on judgments for the $\mathrm{T}$ vs. $\mathrm{O}$ conflict in children (with older kids choosing the transferee more often; probability regression, $\mathrm{p}=.005$ ) and for the $\mathrm{D}$ vs. $\mathrm{C}$ conflict in adults (with less support for the discoverer as age increased; $\mathrm{p}=.009$ ). Age had no effects in any of the other conflicts in children or adults (Supplementary Table 3).

Children provided claim-based justifications for their judgments (in contrast to other unspecific justifications, or no justification at all; see Material and Methods) significantly more often when their decisions favored first possessors (93\% of cases) than when they favored the second characters (76\%; $\left.\chi^{2}[1, \mathrm{~N}=734]=21.24, p<.001\right)$. The proportion of claim-based judgments increased according to school level, although it showed high values at all levels (from $85 \%$ to $95 \%$ across levels; $F[1,108]=7.51, R^{2}=.650, p .007$; full data in Supplementary Table 4).

\section{Discussion}

4.1. Importance of the First Possession Principle in Children and Adults. Our results show that prior possession is more important for children than for adults when deciding ownership.

Previous research has demonstrated the relevance of the first possessor heuristic both in children and in adults [9, 
10]. However, it is easy to create a narrative that does not elicit the application of the first possession principle. For example, let us assume that someone finds wood in the forest and abandons it; ten years later, another person arrives and uses the wood to build a house, where she lives with her family for another ten years. Most people would react to such a story by granting ownership to the house builder. The extent to which the first possession heuristic is applied to a given situation depends on several factors, inherent to the details of a story, that can be manipulated by the researchers. Since the strength of the ownership heuristic is influenced by the story particulars and other contextual variables [25] it is impossible to provide a fixed, absolute measure of the importance of first possession for ownership reasoning. Yet, it is possible to obtain a relative measure: how much children use the first possession principle, compared with adults, for the same scenario. Specifically, we have found that children are significantly more likely than adults to grant ownership to the first possessor of the object under dispute ( $84 \%$ versus $55 \%$ of cases after summarizing all stories, respectively). The greatest divergence between children and adults is obtained when considering Discovery and Creation: $85 \%$ of children's responses vs. $42 \%$ of adults' responses favor the discoverer in stories pitting Discovery against any other claim; $92 \%$ of children's responses vs. $62 \%$ of adults' responses favor creators in the Creation versus Occupation story.

In our opinion, such differences reflect the fact that stories involving Creation and Discovery principles highlight first possession. In this sense, it is interesting that children used claim-based justifications (e.g., "because she built the chair," "because the other boy gave the coin to him") much more frequently when their decisions favored first possessors. When supporting the first possessor, children's judgments are more likely to reflect ownership principles rather than anecdotal details or a personal preference for a certain character.

Our scripts were designed considering that one cannot remove the "first possession" aspect from "discovery" and "creation." In one of the scripts we used, a girl climbs a mountain, discovers a cave, and inscribes her name on the entrance. The act of discovery is an act of appropriation and as such is indistinguishable from "first possession." It is impossible to take apart these factors and say, for example, that the girl's ownership rights are based $60 \%$ on discovery and $40 \%$ on first possession. The very concept of "discovering" means identifying an object that nobody had noticed (seen, touched, grabbed) before and being the first to take possession of it. In this sense, discovery is conceptually closer to first possession than creation, since the latter involves additional factors such as labor, ideas, and transformation of the object identity [26]; in addition, creation is compatible with the possibility that the raw materials belonged to someone else. It appears, then, that first possession (as represented by discovery) has the greatest weight in children's reasoning. In addition, considering all six scripts, discovery was the claim that presented the greater strength difference between adults and children. Our results, therefore, indicate that children's reasoning rests on prior possession significantly more than adults. This conclusion is based on participants' responses to a series of scripts that cover all combinations among four different types of ownership claim, which in turn reflect the main conceptual dimensions of ownership acquisition as elaborated by legal theorists.

The studies by Kanngiesser et al. [22], Kanngiesser, Itakura, and Hood [27], Kanngiesser and Hood [28], Levene et al. [18], and Rochat et al. [5] suggest that, in certain contexts, creation trumps first possession. Of special interest is Kanngiesser et al.s [22] study. In their experiment, a researcher and a study participant borrow clay objects from each other in order to mold them into new shapes. It was found that both preschool children and adults believe that ownership of one person's property is transferred to a second person following the second person's investment of creative labor. In other words, creation overrules the firstpossessor bias. Moreover, this effect was significantly stronger in preschool children than in adults. This result is at odds with our finding that the first possessor bias is stronger in preschool children than in adults. We cannot account for such discrepancy, although we suspect that it stems from the different methodologies employed. Kanngiesser et al. [22] used a first-person experiment: they made study participants bring new objects to existence and decide who the owner was between themselves or the researcher; in contrast, in our study children had to decide between fictional thirdparties. The former is a quite vivid and affective experience that highlights creation while eclipsing first possession.

We acknowledge that many studies have found that creation overpowers first possession, but still believe that the individuals' responses depend on the scripts' specific contents and details. We maintain that creation does not always trump first possession (or the other way around). It is possible to modify the experimental situations in order to tilt the participants' responses one way or the other, and to make them chose creation over discovery (or vice versa). For example, when adults are asked to judge over abstract conflicts involving discovery, creation, and occupation claims, they answer differently depending on whether the second character in the conflict is aware or not that the first one already holds a claim on the disputed good [25]. The "trump" question cannot be decided in an absolute manner, because individuals' responses always depend on many factors and above all on the details of each narrative. The stories in this study included details on physical effort and time involved in feats, or quality of creations, for example, based on the experience from the preliminary pilot study, although the precise effects on judgments of these features demand further study. Yet it is possible to deal with this question in relative terms: by comparing the responses of children and adults to the same narratives, we can determine if children apply certain principles more consistently than adults. Our work contributes to the field and complements previous studies by emphasizing the role of context, by clarifying the relationships between first possession, creation, and discovery, and, above all, by showing that children grant ownership to the first possessor much more consistently than adults. 


\section{Conclusion}

The present study compares the weight children and adults give to four ownership principles (discovery, creation, occupation, and transaction) when reasoning about ownership conflicts. We found that children in our sample relied on discovery and creation significantly more than adults. We argue that first possession cannot be separated from other principles; possession is about control, and there is always control in creation as well as in discovery. Yet, the fact that the principle of first possession is inherent to other principles in different degrees enables us to infer the role played by first possession in children's and adults' reasoning. We found that discovery, as a clear embodiment of first possession, trumps creation and other principles in children's reasoning, at least for the scripts used in our study.

Previous research has established that first possession plays a crucial role in ownership reasoning. However, before our study it was not clear how strong this principle is, and whether children and adults apply this principle in the same way or to the same extent. Our work allowed us to evaluate to what extent children's reasoning is based on first possession, as compared to adults. The results suggest a developmental trajectory that weakens the weight of first possession in ownership reasoning as the child grows. These results can help us make sense of previous research, such as Kim and Kalish's [15] finding that although preschool children recognize transactions, such as sales or gifts, and can correctly identify the new owner of the transferred object, they still grant the original owner some control over the object.

Why do children and adults respond differently? We suspect that children's preference for first possession has its roots in early (perhaps innate) territorial and possessive tendencies as well as in early social interactions, particularly possession conflicts with peers. Thus Bakeman and Brownlee [12] have found that 2-year-olds already acknowledge previous possession in object conflicts among peers. Ross, Tesla, Kenyon, and Lollis [29] have found that toddlers tend to insist one-sidedly on ownership when dealing with possession conflicts (rather than including other considerations, such as fairness or "social peace"), in spite of their mothers' insistence on sharing. Using previous possession as a touchstone to identify owners and nonowners, and using ownership to solve possession conflicts, seems an efficient and practical method for the essentialist mind [30] of young children. As children grow, they start interacting in more complex, institutional environments (such as schools) and become capable of applying impersonal, societal rules and to combine different ownership principles in their reasoning and argumentation. It remains to be determined the precise ages at which children transition from a preponderance of first possession to the adult perspective that incorporates other factors into the equation. Based on extant research [31], we think that this change takes place around 10 years of age. The details of such developmental trajectory, however, are part of a broader research on the ontogeny of ownership and go beyond the focus of this paper, which is about understanding how children apply ownership principles in general and the first possession principle in particular to third-party possession conflicts.

\section{Data Availability}

The data used to support the findings of this study are available from the corresponding author upon request.

\section{Disclosure}

This research did not receive any specific grant from funding agencies in the public, commercial, or not-for-profit sectors. Authors were supported by their affiliation institutions.

\section{Conflicts of Interest}

The authors declare no conflicts of interest.

\section{Supplementary Materials}

The supplementary document contains the following: (i) A description of the pilot study referenced in the Material and Methods. (ii) The full transcripts of every story used in the study in its English translations. (iii) Supplementary Table 1 describing the effect of gender in the judgments by children and adults. (iv) Supplementary Table 2 describing the effects of order of presentation of the conflicts on judgments in children and adults. (v) Supplementary Table 3 describing the effects of age on judgments of children and adults. (vi) Supplementary Table 4 describing the types of justifications used by children for their judgments according to the school level. (Supplementary Materials)

\section{References}

[1] O. Friedman and H. S. Ross, "Twenty-one reasons to care about the psychological basis of ownership," in New Directions for Child and Adolescent Development, vol. 132 of 8, p. 1, 2011.

[2] O. Friedman and K. R. Neary, "Determining who owns what: Do children infer ownership from first possession?" Cognition, vol. 107, no. 3, pp. 829-849, 2008.

[3] S. A. Gelman, E. M. Manczak, and N. S. Noles, “The nonobvious basis of ownership: Preschool children trace the history and value of owned objects," Child Development, vol. 83, no. 5, pp. 1732-1747, 2012.

[4] T. W. Merrill and H. E. Smith, The Oxford introductions to U.S., law: Property, Oxford University Press, 2010.

[5] P. Rochat, E. Robbins, C. Passos-Ferreira, A. Donato Oliva, M. D. G. Dias, and L. Guo, "Ownership reasoning in children across cultures," Cognition, vol. 132, no. 3, pp. 471-484, 2014.

[6] D. Lueck, "Property Law, Economics and," in The New Palgrave Dictionary of Economics Online., Basingstoke:, Palgrave Macmillan, S. N. Durlauf and L. E. Blume, Eds., New Palgrave Dictionary of Economics Online, Palgrave Macmillan, Basingstoke, UK, 2008.

[7] O. W. Holmes, The Common Law, Dover Publications, New York, NY, USA, 1991.

[8] G. W. F. Hegel, "Philosophy of Right," Transition, vol. 1, no. 7, pp. 2055-2068, 2001. 
[9] O. Friedman, W. J. Van de Vondervoort, M. Defeyter et al., "First possession, history, and young children's ownership judgments," Child Development, vol. 84, no. 5, pp. 1519-1525, 2013.

[10] P. Kanngiesser, F. Rossano, and M. Tomasello, "Late Emergence of the First Possession Heuristic: Evidence From a Small-Scale Culture," Child Development, vol. 86, no. 4, pp. 1282-1289, 2015.

[11] O. Friedman and K. Neary, "First possession beyond the law: Adults' and young children's intuitions about ownership," Tulane Law Review, vol. 83, no. 1991, pp. 1-12, 2009.

[12] R. Bakeman and J. R. Brownlee, "Social rules governing object conflicts in toddlers and preschoolers," in Peer relationships and Social Skills in Childhood, pp. 99-111, Springer Verlag, New York, NY, USA, 1982.

[13] D. F. Hay and H. S. Ross, "The social nature of early conflict," Child Development, vol. 53, no. 1, Article ID 1129642, pp. 105113, 1982.

[14] H. S. Ross and C. L. Conant, "The social structure of early conflict: interaction, relationships and alliances," in Conflict in Child and Adolescent Development, C. U. Shantz and W. W. Hartup, Eds., pp. 153-184, Cambridge University Press, New Jersey, NJ, USA, 1995.

[15] S. Kim and C. W. Kalish, "Childrens ascriptions of property rights with changes of ownership," Cognitive Development, vol. 24, no. 3, pp. 322-336, 2009.

[16] M. Verkuyten, J. Sierksma, and J. Thijs, "First arrival and owning the land: How children reason about ownership of territory," Journal of Environmental Psychology, vol. 41, pp. 58-64, 2015.

[17] C. M. Rose, "Possession as the Origin of Property," Faculty Scholarship Series, 1830.

[18] M. Levene, C. Starmans, and O. Friedman, "Creation in judgments about the establishment of ownership," Journal of Experimental Social Psychology, vol. 60, pp. 103-109, 2015.

[19] T. W. Merrill, "Accession and Original Ownership," Journal of Legal Analysis, vol. 1, no. 2, pp. 459-510, 2009.

[20] L. Marshall, "Sharing, Talking, and Giving: Relief of Social Tensions among !Kung Bushmen," Africa, vol. 31, no. 03, pp. 231249, 1961.

[21] O. Friedman, "Necessary for possession: How people reason about the acquisition of ownership," Personality and Social Psychology Bulletin, vol. 36, no. 9, pp. 1161-1169, 2010.

[22] P. Kanngiesser, N. Gjersoe, and B. M. Hood, "The effect of creative labor on property-ownership transfer by preschool children and adults," Psychological Science, vol. 21, no. 9, pp. 1236-1241, 2010.

[23] J. Rawls, A theory of justice, Harvard University Press, 1999.

[24] J. Henrich, R. Boyd, S. Bowles et al., “"Economic man” in crosscultural perspective: Behavioral experiments in 15 small-scale societies," Behavioral and Brain Sciences, vol. 28, no. 6, pp. 795$815,2005$.

[25] L. Casiraghi, G. Faigenbaum, A. Chehtman, and M. Sigman, "Social validation influences individuals' judgments about ownership," Frontiers in Integrative Neuroscience, vol. 12, 2018.

[26] V. Li, A. Shaw, and K. R. Olson, "Ideas versus labor?: What do children value in artistic creation?" Cognition, vol. 127, no. 1, pp. 38-45, 2013.

[27] P. Kanngiesser, S. Itakura, and B. M. Hood, "The effect of labour on ownership decisions in two cultures: Developmental evidence from Japan and the United Kingdom," British Journal of Developmental Psychology, vol. 32, no. 3, pp. 320-329, 2014.

[28] P. Kanngiesser and B. Hood, "Not by labor alone: Considerations for value influence use of the labor rule in ownership transfers," Cognitive Science, vol. 38, no. 2, pp. 353-366, 2014.
[29] H. Ross, C. Tesla, B. Kenyon, and S. Lollis, "Maternal Intervention in Toddler Peer Conflict: The Socialization of Principles of Justice," Developmental Psychology, vol. 26, no. 6, pp. 994-1003, 1990.

[30] S. A. Gelman, “The Essential Child: Origins of Essentialism in Everyday Thought," 2007.

[31] G. Jahoda, "The development of thinking about socio-economic systems," in The Social Dimension, H. Tajfel, Ed., vol. 1, Cambridge University Press, New York, NY, USA, 1988. 


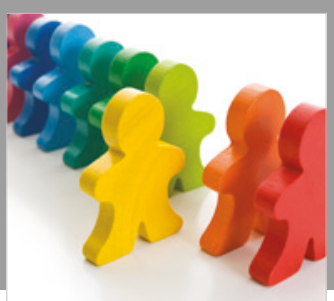

Autism

Research and Treatment
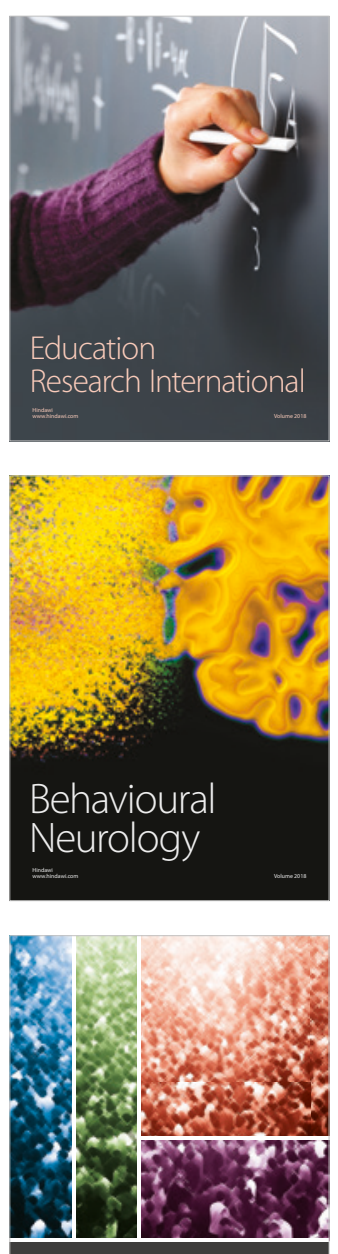

International Journal of

Population Research

$\underline{-m}$

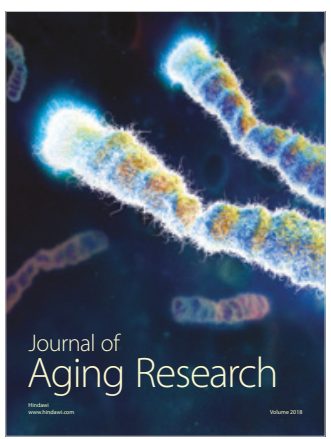

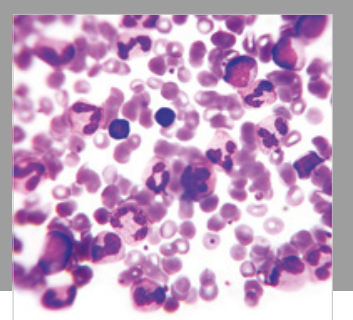

Pathology

Research International$$
=
$$

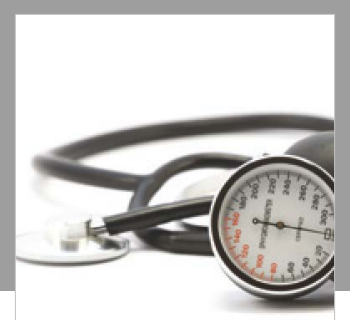

Nursing

Research and Practice

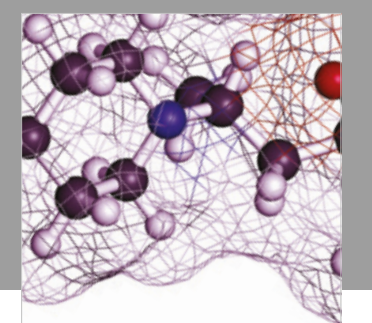

Pain

Research and Management

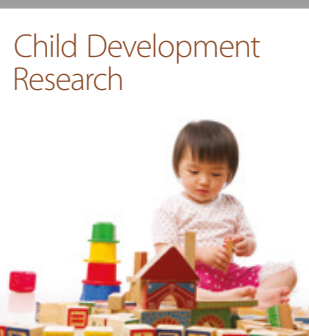

बाD

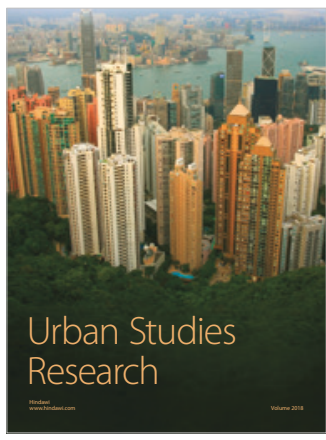

\section{Hindawi}

Submit your manuscripts at

www.hindawi.com
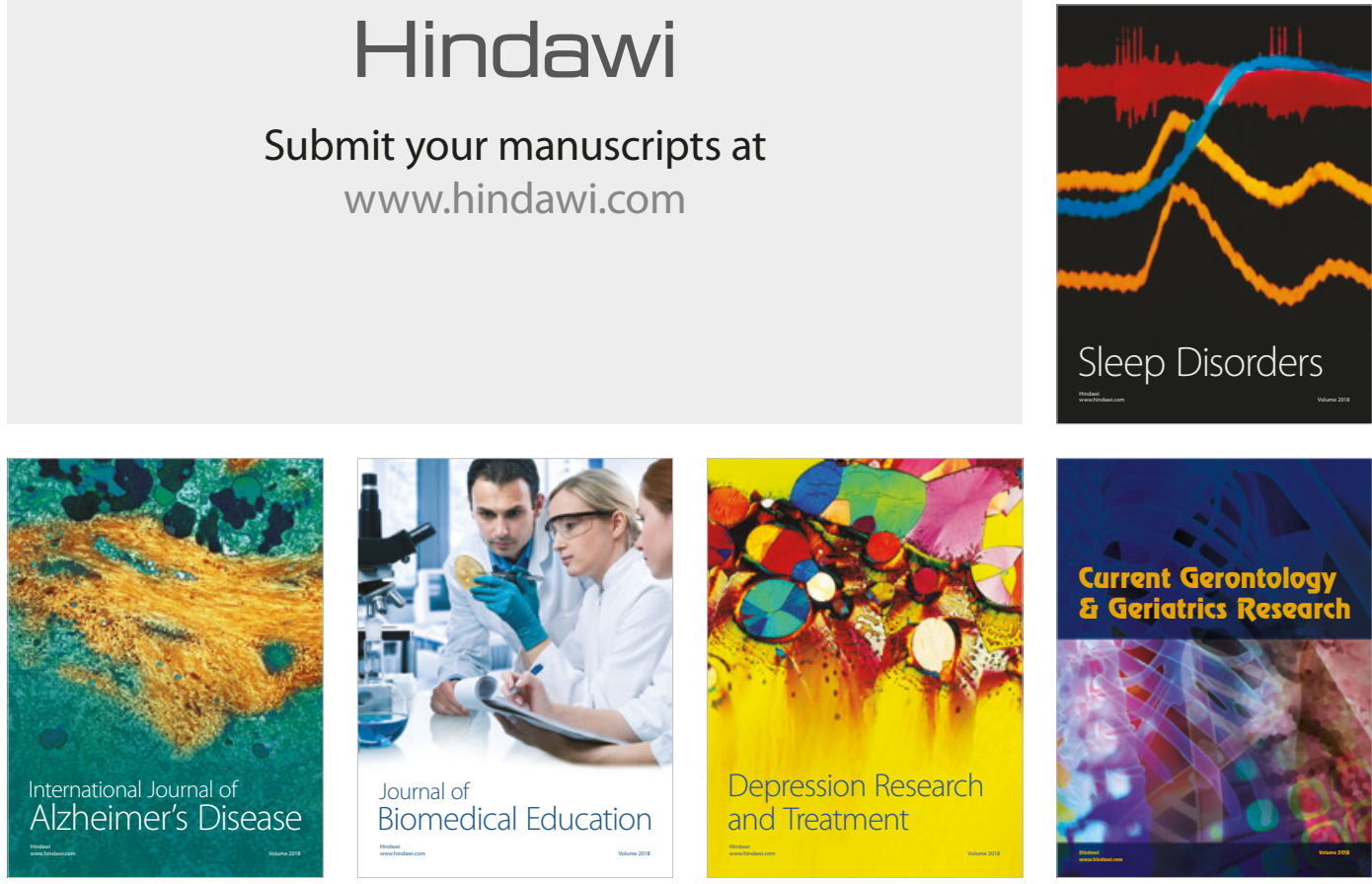

Journal of

Biomedical Education

$=$

smman

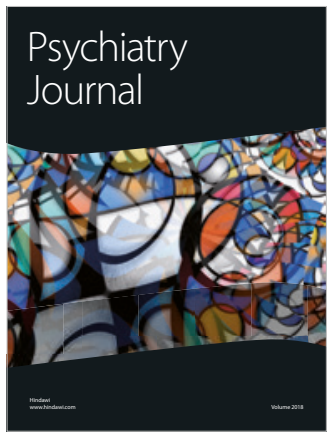

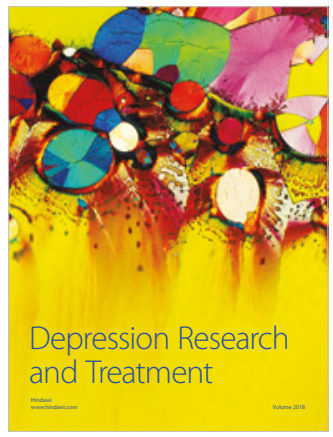
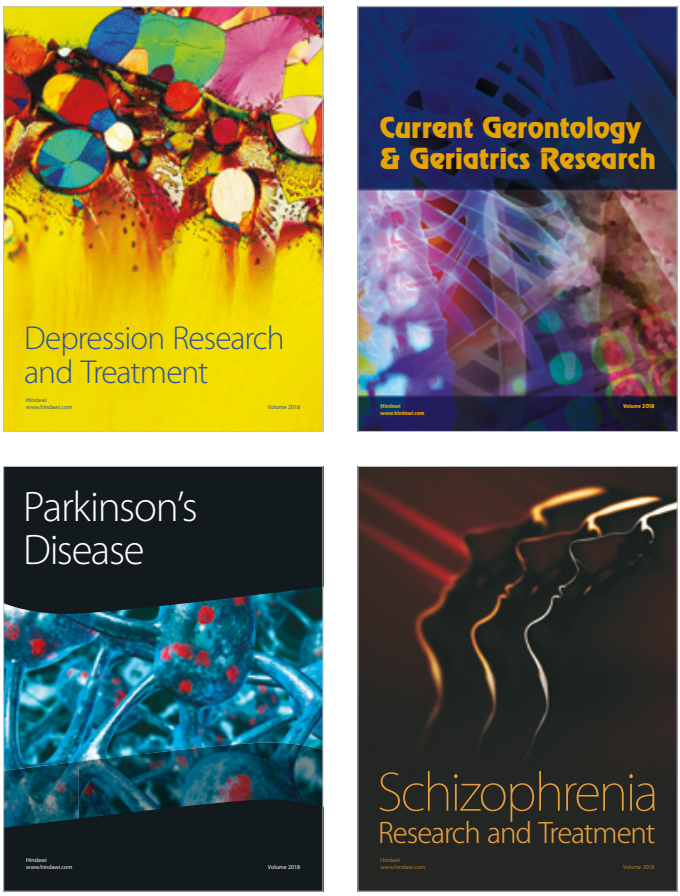